chair in which she had been sitting and there were clonic contractions of her arms and legs. She was conscious after a quarter of an hour, then in a few minutes she went to sleep for the night.

There was no improvement in her mental state following the convulsion. Her medication was restarted and she recovered over the next six weeks; the dose was then gradually reduced and there were no further convulsive episodes.

There was no family or personal history of convulsions, nor any history of conditions which might predispose to these. There was no history of drug or alcohol abuse. No abnormalities were found on physical examination or investigation, the latter having included an electrocardiograph, and electroencephalograph and a brain scan.

The absence of any disorder which could cause, or predispose to, a convulsion makes it possible that drug withdrawal was responsible for the episode. There have been two reports of convulsions following withdrawal of amitriptyline and imipramine (Committee on Safety of Medicines-personal communication) respectively, and thus is would seem that convulsions are a possible risk of abrupt withdrawal of this group of drugs.

Department of Psychiatry,

M. L. Robinson

The University of Liverpool, 6 Abercromby Square,

Liverpool L69 3BX

\section{WARD ROUNDS}

DeAR Sir,

I was interested in the letter in the January 1978 issue of the Journal (132, p 111) from the lady who complained about ward rounds. I have met many fellow psychiatrists who have been unhappy, as I am, with the format of the usual ward round but have been unable to come up with any alternatives. It would be most interesting if you could publish descriptions from other psychiatrists who have successfully tried alternative methods.

Department of Psychiatry,

SAM BAXTER

Charing Cross Hospital (Fulham),

Fulham Palace Road,

London W6 8RF

\section{DeAR SiR,}

How timely it is that a patient should point out some of the faults inherent in psychiatric rounds (Journal, January 1978, 132, 111-12). Perhaps he is also touching on a number of other issues which should concern us as doctors.
Firstly, the issue of patients' confidence that their case is being treated with due regard for their personal privacy. The author clearly feels that this is not the case and that his privacy was indeed intruded upon. It is a familiar psychoanalytical concept that patients find it hard to reveal highly affect-laden material, especially in the presence of an intrusive therapist. How much more applicable this must be to a 'team interview'.

Secondly, the cost benefit of the team round is, by implication, questioned. Many of us must frequently have wondered whether all of the ten or even fifteen persons present at a round might be more usefully occupied. Were such a round to last $2 \frac{1}{2}$ hours it would be equivalent to a full week's work for one person.

It is argued that such events are valuable learning experiences for the team members, but, even ignoring the confidentiality issue, this notion must be regarded with due scepticism. Perhaps the physiotherapist might agree.

We should conduct these clinical activities with greater regard for the ill-effects on our patients and for their cost, just as we do when prescribing drugs.

Or do we feel that our paramedical colleagues would be resentful at being excluded from the decision-making process? Do we now serve the team rather than the patient?

Clinical Psychopharmacology Unit,

P. K. Gillman

Guy's Hospital,

St. Thomas Street,

London SE1 9RT

\section{KNOWLEDGE OF SIDE EFFEGTS AND PERSEVERANCE WITH MEDICATION}

Dear Sir,

In two earlier studies (Myers and Calvert 1973; 1976) we found that forewarning patients of possible side-effects of two antidepressant drugs (amitriptyline and dothiepin) did not affect the incidence of reported side-effects nor did it significantly influence the rate of discontinuance of medication.

Sixty-six patients with primary depressive illness were drawn from attenders at a psychiatric out-patient clinic between May 1974 and June 1976. They were randomly allocated to one of three groups. Patients in Group A were told they were being given a drug to cure their depression; those in Group B were told they were being given a drug to cure their depression and were also told the side-effects they might experience, in which event they were advised to continue the medication; patients in Group $\mathrm{C}$ were given identical verbal information to those in Group $B$ and, in addition, the information was presented in written form for them to take away. 